\title{
México: viagem e autoconhecimento
}

\author{
"Le voyage [est] occasion privilegiée \\ de découvrir du noveau"
} (André Karátson, Voyager dans la Forme Brève).

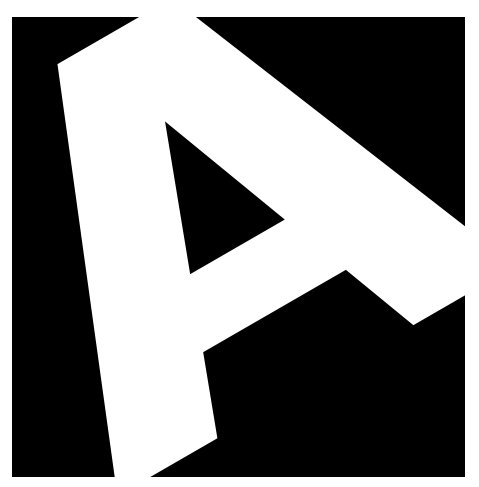

literatura de viagensé um gênero bastante freqüente nas culturas de língua portuguesa, pois, desde o século XIV, quando os navegadores portugueses desbravavam os mares em busca de novas terras, registravam os percalços e o trajeto das viagens e os descobrimentos que faziam, bem como descreviam as terras e os homens que encontravam. Assim, essa literatura está intimamente ligada a fatos extraliterários, ainda que não se atenha apenas ao percurso espacial e temporal do viajante. Importam, muito mais, os motivos que levam o viajante a deslocar-se de um ponto a outro e que são capazes de condicionar sua concretização e sua representação discursiva (Reis, 1994). A viagem representa, normalmente, não só a vontade de romper fronteiras ou limites geográficos, mas também 
o desejo do viajante de, através do conhecimento de novos povos e culturas, pensar de uma maneira diferente o seu próprio eu. Desse modo, segundo Carlos Reis (1994, p. 89), quando se fala em literatura de viagem, não se está a considerar somente aquela literatura que formula o inventário minucioso dos fatos e dos incidentes de uma viagem, mas também os textos "em que a viagem em si mesma constitui elemento temático fundamental” (Reis, 1994, p. 89).

O tema da viagem é bastante trabalhado na obra de Erico Verissimo, não só pelos livros Gato Preto em Campo de Neve, A Volta do Gato Preto, México e Israel em Abril, que relatam viagens e apresentam descrições relativas aos Estados Unidos, México e Israel, como também em seus romances, para cujos heróis a idéia de viajar está ligada a transformações pessoais, à promessa de nova vida, à descoberta de novo mundo. Isso acontece, por exemplo, em O Tempo e o Vento, com personagens como Floriano e Ana Terra. Floriano viaja para os Estados Unidose, quando retorna ao Brasil, começa a escrever a história de sua família. Ana Terra sai da fazenda de seus pais, onde vira a família dizimada pelos castelhanos e onde fora violentada, e viaja para Santa Fé, pretendendo construir nova vida. A viagem que faz com Marciano Bezerra rumo ao povoado é longa e acidentada, e o narrador a relata assim:

“Ana pensou no cofre. Tinha o suficiente para pagar àquela gente pelo transporte e ainda lhe sobraria dinheiro para comprar alguns alqueires de terra. Podiam principiar a vida de novo [...]. Ana pôs a trouxa às costas e subiu com Pedro para dentro duma das carretas [...]. Puseram-se a caminho [...] E assim Ana Terra viu ir ficando para trás a estância do pai [...]. Ao anoitecer acamparam perto de um capão, fizeram fogo e uma das mulheres cozinhou [...]. No dia seguinte antes do raiar do dia retomaram a marcha [...]. E vieram outros dias e outras noites, e houve momentos que até em sonhos Ana Terra continuava a viajar. [...] Quanto tempo fazia que estavam viajando? Ana tinha perdido a conta dos dias. Seguiam a trilha de outras carretas, entravam em picadas, embrenhavam-se no mato, desciame subiam montes [...]. Pelas manhãs as carretas viajavam através da cerração e Ana temia que os bois resvalassem e caíssem todos naqueles precipícios. [...]. Uma tarde avistaram um rio. - O Jacuí [...]. Acamparam e ali ficaram muitos dias porque o Jacuí não dava vau e os homens tiveram de fazer uma balsa. [...] Finalmente a balsa ficou pronta e as carretas atravessaram em duas viagens aquele rio de águas barrentas. [...] E as carretas retomaram a marcha. Equando Anajá pensavaque nunca mais haviam de chegar, Marciano uma tarde fez parar o cavalo junto de um copado umbu e gritou:-Estamos entrando nos campos do velho Amaral. Três dias depois chegavam ao alto de uma coxilha verde onde se erguiam uns cinco ranchos de taipa cobertos de santa-fé. Marciano Bezerra soltou um suspiro e disse: - Chegamos" (Verissimo, 1980a, pp. 121-32). 
A viagem e o romance parecem, em princípio, imbricar-se, sendo que o deslocamento espacial é marca importante da formação do clã de Ana Terra. A jornada cansativa e penosa aponta para o destino da mulher, que terá de ser forte para alcançar seus objetivos.

O tema viagem tem, como se viu, nos romances de Erico Verissimo, valor incomensurável. Aqui, entretanto, não se vai falar dos romances do autor. Optou-se, deliberadamente, por estudar um livro que se apresenta como relato de viagem: México (Veríssimo, 1980b) ${ }^{1}$. Relato de viagem que pode seguir duas vias opostas: seja aquela da viagem, isto é, os fatos da locomoção, as peripécias, as impressões dos viajantes; seja aquela da narrativa, isto é, a maneira de relatar as experiências vividas durante o percurso. A obra escolhida descreve uma viagem cujo ponto de partida ou de chegada é Washington, limite que é necessariamente ultrapassado, porque o fim principal, para o escritor Erico Verissimo, não é dar conta da aventura da viagem ao México, mas sim desvendar como essa viagem é reveladora de seu mundo interior.

Publicadoem 1957 e redigido no período de 1953-56², quandoo escritor se encontrava nos Estados Unidos, Méxicoé uma narrativa que mostra que Erico Verissimo tem consciência do caráter único e irrepetível de sua vida e, por isso, decide fazer um documento para lembrar sua viagem ao México. Trata-se de um diário de viagens cujo caráter ulterior do ato de narrar é extremamente acentuado por configurar-se como memória. Nesse relato de viagem, fica explícita a situação do narrador em relação ao que narra; nele, o estatuto de viajante autoriza o narrador autodiegético ${ }^{3}$ a retomar de modo muito pessoal um acontecimento singular - sua visita ao México. Organizando os acontecimentos numa versão definitiva, ele "procurará narrar uma história que conhece em sua totalidade" (Buttor, 1969, p. 77). Voltado para o exterior e acolhendo impressões de viagem, comentários de leituras, reflexões políticas, estéticas, morais, religiosas, esse relato apresenta-se, por essência, como espaço de fundação e reconhecimento do $e u$, tornando-se exercício intelectual e oficina de idéias.

Sabe-se que o diário (íntimo ou de viagens), um dos gêneros da literatura autobiográfica, é o confidente tanto do homem público quanto do homem privado, tanto do escritor ilustre quanto do adolescente fechado em seu quarto ou da mulher a quem, ao longo da história literária, nem sempre esteve aberto o acesso à publicação (Rocha, 1992, p. 28). Seu estatuto é o da confidência, a extroversão de um fato para um amigo que é o caderno em que se anotam viagens e/ou a vida íntima. Decorre, assim, de uma necessidade de comunicação do eu consigo mesmo ou com os outros. Conseqüentemente, a tendência descritiva, privilegiada pela narrativa de viagens e estimulada pela autoridade do narradorviajante que conhece muito mais que os seus leitores, alterna-se com a digressão, porque o sujeito que se desloca no espaço mexicano empreende uma viagem ao seu interior: "[...] uma viagem de natureza ideológica e de intenção didática, autorizada pela experiência adquirida e constituída por digressões intelectuais, através de valores e de sentidos culturais descobertos a partir da primeira [...] viagem" (Reis, 1994, p. 91), aquela realizada ao México.

Porque nasce de uma situação unilateral de comunicação, em que o destinador e o destinatário são uma e a mesma pessoa, o diário (íntimo ou de viagens) pode transformar essa situação em partilha com os outros, tornando-se lugar de um duplomovimento de interiorização e exteriorização. Ao ser publicado, como foi o relato de Erico Verissimo, é introduzido no sistema de consumo coletivo, deixando de lado seu caráter privado. Entretanto, segundo Clara Rocha (1992, pp. 29-30), mesmopassandoaodomíniopúblico e, portanto, quebrando a intimidade, o diário (íntimo ou de viagens) pode continuar mantendo um efeito de intimidade, através de um estilo menos elaborado, da descontinuidade da escrita e pelo registro de um cotidiano por vezes trivial e repetitivo.

México estrutura-se de maneira bastante original, pois, apesar de ser um diário de viagens, não é marcado por datas, mas pela 
justaposição de numerosos microrrelatos, cuja disposição hierarquizada forma o espaço autobiográfico, revelando o pendor auto-reflexivo de Erico Verissimo. Não constituindo uma unidade significante romanesca, essa estrutura paratática pode ser considerada como uma necessidade - inerente ao motivo viagem - de guardar, preservar, salvar experiências vividas; de o escritor autoconhecer-se e de isolar-se na escrita.

A descontinuidade, o fragmentarismo, sinais característicos quer do diário íntimo, quer do diário de viagens, são os elementos que diferenciam esse gênero do romance autobiográfico. Tais elementos estão presentes no texto de Erico Verissimo. Tanto assim que, seguindo um modelo de narração em que a enunciação alterna com o acontecimento dos fatos narrados, mesmo sem recorrer à datação, o relato segue uma ordem cronológica, obedecendo o narrar dos fatos à sucessão dos dias, ao trânsito para espaços diferentes. Propõe, desse modo, uma leitura descontínua que não prejudica a compreensão do texto.

Formalmente, México apresenta 12 partes ou capítulos, emoldurados por um prólogo e por um epílogo. Cada capítulo compreende em média de 5 a 20 subcapítulos (num total de 158), todos titulados e marcados, cada um, por elementos temáticos que apontam para o desdobramento do $e u$ em duas personae: um homem vivido e um homem que vive; um narrating self e um experience self, um pai de família e um herói nômade, o sábio e o aventureiro, o que escreve e o que age.

O conjunto de microrrelatos que constitui México é uma seqüência circular que se abre no prólogo, quando, numa evocação humorística, Erico Verissimo, autor-personagem-narrador ${ }^{4}$, delimitando o espaço narrativo, diz:

\section{“-Vamos ao México?}

Atirei a pergunta ao chegar a casa naquele anoitecer de abril. Era em Washington e as cerejeiras estavam floridas à beira do Potomac. Minha mulher, que lia o Evening Star, ergueu a cabeça e pousou em mim os olhos azuis.
- México ? - repetiu ela com ar vago e tornou a baixar a cabeça, o olhar e a atenção para o jornal.

Pondo mais convicção na voz, repeti o convite:

- Vamos mesmo ao México?

Naquela noite a Família discutiu longamente o assunto à mesa do jantar. Como Madame tem horror às viagens de avião, decidimos enfrentar as agruras duma jornada de trem. Os filhos ficariam, seguindo a rotina, enquanto os pais trilhassem os caminhos da aventura.

E uma bela manhã nos encontramos com armas e bagagens na plataforma de El Paso, no Texas, esperando o trenzinho que nos levaria à cidade de Juárez, do outro lado do rio, já em território mexicano",

o que se fecha, no epílogo, quando o narrador Erico afirma:

“Estamos de volta a Washington. Já retomamos a doce rotina familiar. Nossa casa de repente se mexicanizou: são zarapes no chão, nas paredes e em cima das poltronas; cestos de Toluca pelos cantos; os caballitos domestre Timóteo em cima da lareira; vasos, bilhas e pratos de Oaxaca e Guadalajara em armários e prateleiras...

É bom estar de volta. Tenho de confessar a mim mesmo que já sentia falta desta ordem, desta limpeza, deste conforto.

Mas ai! o tempo passa, a saudade do México começou a assaltar-me com tanta frequiência que termino numa confusão de sentimentos.

Eu sabia que o epílogo deste livro não podia ser feliz! Estou talvez condenado a oscilar o resto da vida entre esses dois amores, sem saber o que mais desejo, se o mundo mágico ou o mundo lógico. Só me resta uma esperança de salvação. É a de que, um dia, entre a tese americana e a antítese mexicana, o Brasil possa vir a ser um dia a desejada síntese. Y quiém sabe?",
4 Conforme Lejeune (1976), a identidade autor-personagemnarrador, no nível do texto, assegura o pacto autobiogrático, elemento fundamental na caracterização da autobiografia e na distinção desta da ficção de fundo autobiográfico. 
revelando que, ao retornar de sua viagem, encontra-se dividido entre a organização da vida americana e a desordem mexicana. E a narrativa volta, assim, ao ponto de partida, a casa do escritor em Washington.

Entre a abertura e o fechamento do livro, podem-se considerar diferentes viagens. A primeira, mote da narrativa, o deslocamento para e no México. A segunda soma ao fato de o narrador penetrar no universo mexicano a sua evolução pessoal e interior. Isso é marcado na narrativa pela representação envolver passados já vividos em muitas de suas viagens pelos países da América Espanhola. A quarta viagem, pela história do México, está representada pelo diálogo do narrador-viajante com os dados factuais da história mexicana. Então, em México, a separação exterioridade/interioridade, marcada pela relação que se estabelece entre a viagem de fato e aquela que o autor faz ao seu interior, dois mundos aparentemente sem pontes, dilui-se no momento em que a personagem narradora pressente

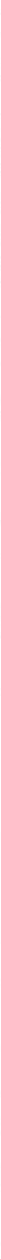

de um homem que viveu os fatos relatados ativamente; esses fatos transformam esse eu num homem mais pleno e mais maduro

Erico Verissimo

e o filho Luis

Fernando,

Porto Alegre,

1973 que acaba por subordinar o tempo histórico, de que foi testemunha, a um tempo humano (Ricoeur, 1983, v. 3, p. 85). A terceira mostra o reencontro de Erico Verissimo com suas raízes latinas. Afastado do Brasil, ao reencontrar os latinos, sua narrativa vai e expressa a interioridade através do relato exterior visível para os olhos:

"Estamos sentados na platéia do Teatro de Variedades. Na realidade, encontro-me em outro ponto do tempo e do espaço. Isto não é Puebla, mas várias cidades do passado fundidas numa só por obra de um daqueles prestidigitadores da minha infância. $\mathrm{O}$ 
ano? 1915. Dizem que mataram Pinheiro Machado e que a situação é muito séria. Como se essa desgraça não bastasse, continua a Grande Guerra na Europa. Mas que importa? Meus pais me deram licença para vir hoje assistir El Gato Montés e aqui estou ansioso por ver erguer aquele pano de boca vermelho em cujo centro, num medalhão fingindo relevo, querubins esvoaçam com guirlandas gordas nas mãos.

Minha companheira me toca no braço, chamando-me de volta a Puebla. Faz um sinal na direção da esquerda. Olho. Uma mulheraça poblana dá de mamar ao filho, que lhe chupa o seio, produzindo um líquido ruído de sucção.

- Imagina tu - cochicho - se aqueles querubins de pano farejam o leite e se precipitam sobre essa senhora...

- Te juro [diz a companheira] como ela não se perturbaria e daria também o seio aos anjinhos..." (p. 126).

Esse fragmento revela a superação da situação narrativa tendencialmente objetiva "Estamos na platéia do Teatro de Variedades" por uma atitude subjetiva em que o narrador, reafirmando sua centralidade isola-se e veicula as lembranças de sua infância, reacendidas pelo espaço em que se encontra. O texto torna-se ambíguo, pois o dêitico temporal, hoje, e o espacial, aqui, em vez de mostrarem a situação narrativa presente, apontam simultaneamente para o passado e para o presente. Os dois planos temporais confundem-se. Isso explicita o movimento de exteriorização e interiorização, sendo que a personagem-narradora só retorna ao exterior quando: "Minha companheira me toca no braço, chamando-me de volta a Puebla".

Assim, recordando etapas de sua existência, Erico Verissimo obriga-se a situar o que vê hoje na perspectiva do que viu ontem, incentivando a curiosidade dos seus leitores e transformando-os não apenas em testemunhas de sua história particular, mas em testemunhas de uma época cultural: aquela em que "mataram Pinheiro Machado" e em que se desenrolou a "Grande Guerra”. Realiza, nesse trânsito entre exterioridade e interioridade, entre presente e passado, uma leitura segunda da experiência vivida, que lhe parece mais verdadeira, porque dela tem consciência. Arecordação, a lembrança, dá ao narrador homoautodiegético novas perspectivas e permite considerar a complexidade de determinada situação no tempo e no espaço.

Constata-se, portanto, que o melhor estimulante de suas representações imaginárias, as quais se inserem no relato através de associações elaboradas pelo sujeito da enunciação no momento da escrita, ou porque vieram à lembrança da personagem ao desenrolar da ação, é o deslocamento que faz e os sítios que visita no México. Mas não é só isso, sua viagem real faz reviver involuntariamente outras viagens ${ }^{5}$, outros lugares, com uma intensidade excepcional:

“Aqui há de tudo. Diz-se que é possível aparelhar, mobiliar uma casa inteira sem precisar sair da Lagunilla. A freguesia é a mais variada e, como era de esperar, vai desde o homem do povo, interessado no ferro-velho, passando por membros da classe média à procura de pratos, talheres, uma banheira, uma compoteira ou uma lâmpada, até o membro do Café Society em busca de artigos de prata, móveis e quadros antigos, ou o artista e o colecionador à cata de retábulos, ex-votos, crucifixos...

Lembro-me da feira de Maxwell Street, no bairro judeu de Chicago, que visitei em 1941 numa gélida manhã de inverno. Que contraste entre aquela feira e esta! Lá predominavam as epidermes claras e os cabelos loiros. Aqui as caras morenas e as cabeleiras escuras. Lá névoa, aqui sol. Na Maxwell Street [...] os vendedores eram mais agressivos, mais teatrais e alguns deles faziam discursos aos berros, apesar de apregoarem artigos pouco interessantes. Aqui tudo se processa em silêncio ou em voz baixa, à melhor maneira índia" (p. 66).

Quando visita a feira de Langunilla, Erico Verissimo lembra-se da feira de Maxwell Street, de Chicago, e, comparando as

\footnotetext{
Sabe-se que, enquanto esteve em função diplomática cultura na OEÁ, Erico Verissimo viajou por muitos países latinos.
} 
duas, ao mesmo tempo confronta culturas diferentes: a americana e a mexicana. Da feira real "viaja" para outra feira, visitada em um tempo passado. A viagem e o confronto de civilizações tornam-se, assim, pretextos para o autor-narrador personagem relativizar idéias e conceitos preconcebidos.

A mesma intensividade afetiva faz com que Erico Verissimo, ao descrever lugares que visita, durante sua viagem, aprenda a perceber o mundo de outra forma, comportando-se como um viajante curioso e instruído que procura informar-se junto ao povo, e que relaciona as informações colhidas com experiências vividas ou com suas leituras, as quais partilha com o leitor

Mescla de saudosismo e culturalismo, México é também o espaço em que Erico Verissimodemonstra a preocupação didática. O conjunto de microrrelatos revela o gosto de partilharos conhecimentos mais diversos: paisagens, traços caracteriológicos, rituais, episódios históricos, leituras. É também o espaço que abarca vários níveis de língua e várias esferas específicas de linguagem. Desde o tom erudito até o popular, desde o léxico específico da música ou das artes plásticas até o da história, tudo se une numa explosão de palavras que fascina o leitor, tornando-o seu companheiro de viagem.

\section{BIBLIOGRAFIA}

BUTTOR, Michel. Essais sur le Roman. Paris, Gallimard, 1969.

LEJEUNE, Phillipe. Le Pacte Autobiographique. Paris, Seuil, 1976.

REIS, Carlos. “0 Discurso da Peregrinação: Narrativa, Viagem, Tempo”, in BHS, v. 71, 1994, pp. 87-95.

RICOEUR, Paul. Temps et Récit. Paris, Seuil, 1983.

ROCHA, Clara. Máscaras de Narciso: Estudos sobre a Literatura Autobiográfica em Portugal. Coimbra, Almedina, 1992.

VERISSIMO, Erico. 0 Continente, 20ed., in Obra Completa de Erico Verissimo. Porto Alegre, Globo, 1980a, t.1. México, 60 ed., in Obra Completa de Erico Verissimo. Porto Alegre, Globo, $1980 \mathrm{~b}$. 

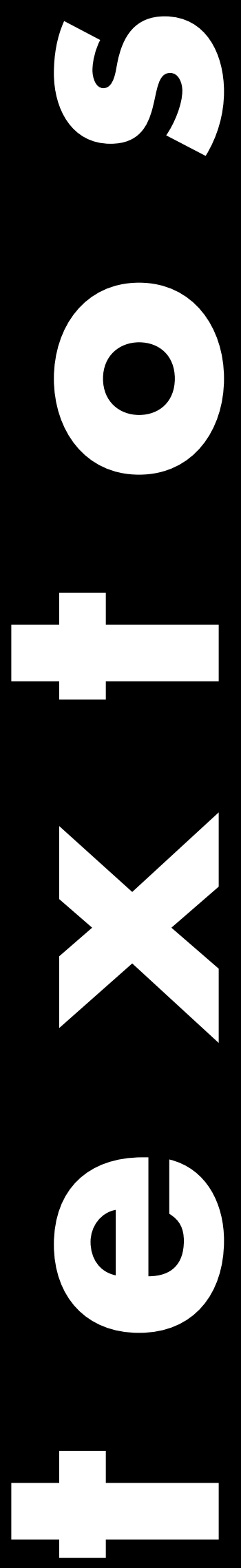